\title{
Response Proliferative Capacity of Undifferentiated Stem Cells of Obtained Human Adult Dental Follicle
}

\author{
Larissa Kim Higashi de Carvalho, ${ }^{1,2}$, Aline Vieira Pinheiro de Araujo ${ }^{1,2}$, \\ Manuela Garcia Laveli da Silva1,2, Rosa Andréa Nogueira Laiso, ${ }^{1,2}$, \\ Durvanei Augusto Maria2 ${ }^{*}$ \\ ${ }^{1}$ Faculty of Medicine, University of Sao Paulo, Sao Paulo, Brazil \\ ${ }^{2}$ Laboratory of Biochemistry and Biophysics, Butantan Institute, Sao Paulo, Brazil \\ Email: ${ }^{\text {durvanei@usp.br }}$
}

Received 27 August 2014; revised 25 September 2014; accepted 18 October 2014

Copyright (C) 2014 by authors and Scientific Research Publishing Inc.

This work is licensed under the Creative Commons Attribution International License (CC BY). http://creativecommons.org/licenses/by/4.0/

(c) (i) Open Access

\section{Abstract}

Objective: The aim of this study was correlation proliferative activity, markers express stem cells, and lipid peroxides of undifferentiated stem cells of human adult dental follicle (DF) following culture. Methods: For this study, we used 8 samples from DF of impacted third molars to maintain culture conditions and evaluated the growth curve, cell viability, production of lipid peroxidation, cell cycle phases, and proliferative index during 25 days of culture. Results: Cells after culture showed characteristics of fibroblast-like type following 25th day of culture. The results of lipid peroxidation showed that stem cells in culture produce $13 \mathrm{nmoles} / \mathrm{ml}$ malondialdehyde at the start of culture, increasing until the 12th day and then began a decline that lasted until the 25th day. We revealed that DFSCs presented a significantly higher percentage of cells in $S+G 2 / M$ phases by the 15th day of culture compared with cells at the start of culture. Cell surface markers revealed that cell lines were negative for HLA-DR and positive for CD90, CD44, and CD105. The expression of $\mathbf{2 1}$ protein, involved in the regulation of the cell cycle, showed a significant increase from the 15th to 25th day of culture. Results of cell division rates show a significant increase between the 6th and 15th day of culture. Conclusions: We conclude that the culture remained stable during the 25 days of culture, presenting the markers of stem cells and markers of control, progression, and cell proliferation that there was an increased production of lipid peroxides between the 6th and 12th days; this increase is related to the increased numbers of cells that also occurs during this period. Then, there is a significantly decline in the production of lipid peroxides and the number of cells, which is accompanied by an increase in cell unviability.

\footnotetext{
"Corresponding author.
} 


\section{Keywords}

\section{Follicle Dental Stem Cells, Lipid Peroxidation, Cell Cycle, Proliferation}

\section{Introduction}

Mesenchymal stem cells (MSCs) are undifferentiated cells that are able to self-renew, have a high proliferative capacity, and have the capacity to differentiate into various types of cells [1] [2].

In human postnatal dental tissue, 5 different sources of MSCs have been already identified: dental pulp, periodontal ligament, exfoliated deciduous teeth, dental follicle, and apical papilla. These dental tissue stem cells are mesenchymal stem cells embryologically derived from both neural crest and mesenchyme [3]-[7].

The adult stem cells (ASCs) are non-differentiated and play important roles in maintaining tissue integrity in vivo through both normal tissue renewal and pathological tissue regeneration [8].

Particularly dental follicle (DF) is a loose connective tissue sac derived from ectomesenchymal tissues. This tissue contains progenitor cells that form the periodontium, i.e., cementum, periodontal ligament, and alveolar bone. In addition, the dental follicle is also critical for the coordination of tooth eruption. It surrounds the developing tooth and plays different roles during the life of a tooth. DF is formed at the cap stage of tooth germ development by an ectomesenchymal progenitor cell population originating from cranial neural crest cells. During the tooth eruptive process, it remains adjacent to the tooth crown of unerupted or impacted teeth. DF also regulates osteoclastogenesis and osteogenesis for eruption. As the tooth erupts, the DF differentiates into the periodontal ligament that anchors the tooth to the surrounding alveolar bone in its socket. Alternatively, under pathological conditions, the DF can proliferate into stratified squamous epithelium to generate dental cysts. Hence, it has several key functions in both the development of the periodontium and resorption of bone during tooth development [9]-[11]. Precursor cells have been isolated from human DF of impacted third molars. Similar to other dental stem cells, these cells form low numbers of adherent clonogenic colonies when released from the tissue following enzymatic digestion [11]. Studies have shown that dental follicle stem cells (DFSCs) have typical ASCs properties of self-renewal, colony formation, and multi-lineage differentiation. Dental stem cells represent a good treatment option in regenerative dentistry. Regeneration of large bone defects can be achieved by a cell-based therapy consisting of osteogenic progenitor cells, such as DFSCs [12]. DFSCs represent an attractive alternative stem cell source because of the fact that they are easily obtainable from extracted third molars [13]-[17]. For a long time, reactive oxygen species (ROS) have been considered as unavoidable by products of oxidative damages. Support for this notion stems from the fact that ROS produced by mitochondria during normal metabolism is toxic to cells [18]. Low-to-moderate levels of ROS are essential for cellular proliferation, differentiation, and survival [19] [20]. Increased levels of ROS lead to oxidative stress and damage to critical biomolecules, resulting in deleterious biological effects. ROS induce lipid peroxidation. Lipid hydroperoxides are non-radical intermediates derived from unsaturated fatty acids, phospholipids, glycolipids, cholesterol esters, and cholesterol itself. When ROS interact with polyunsaturated fatty acids in membranes or lipoproteins, the process of lipid peroxidation begins. In the resulting lipid peroxidation, fatty acids are transformed to the primary product of lipid peroxides. Uncontrolled production of lipid peroxides can cause oxidative stress, with significant damage to cell integrity [21]. In contrast to the damaging effects of ROS, there is evidence that in some systems ROS at lower, non-toxic levels can actually promote cell proliferation and survival. These findings suggest a much more complex role for redox balance in cellular biology than was first understood by models of oxidative stress [22].

The aim of this study was correlation proliferative activity, production of lipid peroxidation, markers expression, progression cell cycle, and mitochondrial potential in undifferentiated stem cells from human adult dental follicle during culture conditions.

\section{Methods}

\subsection{Patients}

We studied eight patients referred to our clinic integrated for removal of asymptomatic fully impacted third mo- 
lars were enrolled in this study. Exclusion criteria included a history or sign of infection or enlarged tissues surrounding the impacted third molars. Approval for the study was obtained from the local ethics committee, and informed consent was obtained from all the participating patients. It is confirmed that Helsinki Declaration was read, and the researchers followed the guidelines in this investigation. All operations were carried out under local anesthesia by conventional third molar surgery. This study was approved by the Ethics Committee of the Cruzeiro do Sul University and all participants gave their informed consent.

The dental follicles were obtained from extraction of impacted third molars. The dental follicle was placed immediately after its withdrawal in a sterile glass pot and them the samples were rapidly transported to the laboratory and placed in the lid of a culture dish and with scissors and tweezers the dental follicle was cut into several small fragments. Was added $1 \mathrm{ml}$ of culture medium DMEM/F12 (Sigma-Aldrich, St. Louis, MO) and supplements. The tissue was then macerated using the plunger of a sterile hypodermic syringe in a laminar flow.

\subsection{Cell Culture}

Dental follicle (DF) stem cells were cultured in culture plate with 24 wells in DMEM/F12 (Sigma-Aldrich, St. Louis, MO) medium supplemented with 1\% L-glutamine, 1\% non-essential aminoacids, 1 mm sodium pyruvate, $1 \%$ antibiotics and 15\% fetal bovine serum (Hyclone, South Logan, UT, USA). Cells were incubated at $37^{\circ} \mathrm{C}$ in a humidified atmosphere with $5 \% \mathrm{CO}_{2}$. Cells were observed three times a week, and at these same times, medium was changed totally. Detached cells were centrifuged twice and addition in culture medium; cell concentration was adjusted to $5 \times 10^{4}$ cells $/ \mathrm{ml}$ and counted in a Mallassez chamber. Morphological aspects of dental follicle stem cells were observed using an inverted light microscope (Olympus CKX41); a digital camera (Sony DSC-H70) was used to record digital micrographs.

The fragments were put into a culture plate with 24 wells and added $1 \mathrm{ml}$ of culture medium. The plate was carried into the oven at $37^{\circ} \mathrm{C}$ in a humidified atmosphere with $5 \% \mathrm{CO}_{2}$. The supernatant from each well was used and transferred to eppendorfs placed in the freezer to lipid peroxidation assay. For either culture, upon confluence, the cells were trypsinized and passaged into new flasks until the desired passages were obtained. To carry trypsinization culture plate to flow, the culture medium was removed from the well using a pipette and added trypsin $0.25 \%$ (Invitrogen, Carlsbad, CA, USA), for 2 minutes and then the same is inactivated by adding $400 \mu \mathrm{l}$ in the culture medium. After centrifugation, resuspend the DFSCs pellet in $1 \mathrm{ml}$ of freezing medium (90\% FBS and 10\% DMSO Sigma-Aldrich, St. Louis, MO, USA), cryovials designed for liquid nitrogen storage.

The number of viable cells was determined by exclusion technique of non-vital cells were stained with trypan blue (Invitrogen, Carlsbad, CA, USA). The cell suspension was transferred to a Malassez chamber and the cells were counted, excluding those that are showing blue staining (nonviable cells).

\subsection{Flow Cytometry for Cell Phenotype}

For phenotypic characterization of cell lines, cells were cultured for 48 hrs and then harvested in $0.25 \%$ trypsin/EDTA. Aliquots of $10^{6}$ DFSCs were labelling with FITC-conjugated human anti-mouse CD44 (BioLegend, San Diego, CA, USA), CD90 (Cedarlane, Ontario, Canada) in $100 \mu$ l of phosphate buffer saline (PBS) containing $2.5 \%$ BSA and $0.1 \%$ sodium azide for $45 \mathrm{~min}$ on ice according to the manufacturer's instructions. For nonconjugated human anti-mouse CD105 (Santa Cruz Biothecnology, Santa Cruz, CA, USA) and HLA-DR (Abcam, Cambridge, MA, USA) antibodies, the cells were incubated with each first antibody for 45 min, and then labelling with secondary mouse anti-human IgG-FITC (Abcam, Cambridge, MA, USA) for another 45 min.

\subsection{Measurement of Mitochondrial Membrane Potential ( $\Delta \psi \mathrm{m})$}

The mitochondrial transmembrane potential $(\Delta \psi \mathrm{m})$ was measured by rhodamine (Rho123) assay, monitored by flow cytometry. DF stem cells at density of $10^{5}$ cells were plated in 6-well plates and incubated for 24 h. Rho 123 was added at $100 \mathrm{mg} / \mathrm{l} 30 \mathrm{~min}$ before analysis. After washing with PBS, the cells were analyzed using a FACScan flow cytometry system (Scalibur-Becton Dickinson, San Jose, CA). A total of 10.000 cells/sample were analyzed and the mean fluorescence intensity and percentage of cells was recorded. M1-Mitochondria population active and M2-Mitochondria population inactive.

\subsection{Expression of Bcl-2, Cyclin D1, Cytochrome C, p21 and PCNA by Flow Cytometry}

DFSCs were labelling with Anti-IgG antibody (ab170461) (Abcam, Cambridge, MA, USA), used control assay 
flow cytometry. Cells were first fixed and permeabilized with Triton X-100 0.02\%, then labelling with FITC labeled anti-BCL-2 (Abcam, Cambridge, MA, USA ), Cyclin D1 (Abcam, Cambridge, MA, USA), Cytochrome C (Abcam, Cambridge, MA, USA), p21 (Abcam, Cambridge, MA, USA ) and PCNA (Abcam, Cambridge, MA, USA) antibodies or isotype control antibody (Abcam, Cambridge, MA, USA). The percentages of cells expressing Bcl-2, Cyclin D1, Cytochrome C, p21 and PCNA were performed using a FACScan flow cytometry system (Becton Dickinson, San Jose, CA, USA). A total of 10.000 cells/sample were analyzed and the mean fluorescence intensity and percentage of cells was recorded.

\subsection{Determination of Cell Cycle Phases}

DFSCs were synchronized by deprivation of serum for $24 \mathrm{~h}$ and induced to reenter the cell cycle by the subsequent addition of serum. Then, cells were collected and fixed with cold $70 \%$ ethanol and stored at $-20^{\circ} \mathrm{C}$. Cells were washed and resuspended in PBS solution and were incubated at $37^{\circ} \mathrm{C}$ for $45 \mathrm{~min}$ with $10 \mathrm{mg} / \mathrm{ml}$ RNase, 0,1 $\mathrm{mg} / \mathrm{ml}$ Triton-X and $1 \mathrm{mg} / \mathrm{ml}$ propidium iodide (Sigma, St. Louis, MO), then incubated for $30 \mathrm{~min}$ at $37^{\circ} \mathrm{C}$ and analyzed by flow cytometry. Flow cytometry was applied to determine kinetic parameters of the cell populations and to provide percentages of cells that were in G0/G1, S, and G2/M phases, as well as those undergoing apoptosis or DNA fragmentation [23]. The analysis was performed using a FACScan flow cytometry system (Becton Dickinson, San Jose, CA). The percentage of cells in the different cell cycle phases was determined using Modfit LT software (Verity Software House, Topsham, ME).

\subsection{Determination of Cell Viability-MTT Assay}

DFSCs in $6,10,12,15,18,21$ and 25 days of culture were seeded at a density of $10^{4}$ cells in 96-well tissue culture plates (Corning Inc., NY, USA) incubated for $24 \mathrm{~h}$. Measurements of cell proliferation were obtained using the MTT (3-(4,5-dimethylthiazolyl-2)-2,5-diphenyltetrazolium bromide) method [24]. MTT is a widely accepted method that utilizes reduction of tetrazolium salts in evaluation of both cell proliferation and cell death. After dissolution of the Formazan's crystal, a spectrophotometer (Biorad, CA, USA) was determined optical density at $570 \mathrm{~nm}$ proportional to number of live cells.

\subsection{Determination of Cell Division Rates of Dental Follicle Stem Cells}

Methods used to perform proliferation analysis using CFSE (5,6-carboxyfluorescein diacetate succinimidyl ester) have been described previously [25] that allows for direct detection of single proliferating cells, and facilitates quantification of cell division by flow cytometry, according to respective CFSE-dilution. The principle of analysis of DFSCs is as follows: CFSE is divided equally into daughter cells following cell division, and intensity of fluorescence is half that of the parental generation. Thus, in a whole cell population that is undergoing proliferation, fluorescence intensity declines by half in the following generation [26]-[29]. CFSE flow cytometric data files were analysed using CellQuestTM acquisition/analysis software (Becton Dickinson, San Jose, CA). Fifty thousand events were collected, and population proliferation was analysed using ModFitLT2.0 software (Proliferation Wizard Analysis).

\subsection{Lipid Peroxidation (TBARS)}

The oxidative stress over the unsaturated lipids in cell membranes was evaluated by determining the amount of malondialdehyde (MDA), which is the final product of fatty-acid peroxidation, which reacts with thiobarbituric acid (TBA) to form a colored complex. Thiobarbituric acid reactive substances (TBARSs) are quantified by spectrophotometric determination [30].

\subsection{Histopathological Analysis}

For light microscopy, DF were fixed in $10 \%$ formaldehyde. Then, samples were washed in PBS, followed by dehydration in a series of ethanol solutions at increasing concentrations ( $70 \%$ to $100 \%)$ for one hour in each solution. Sections were then diaphanized in xylene for 2 hours and embedded in paraffin (Histosec-MERCK, lot K91225309, Brazil). The paraffin blocks were sectioned at $5 \mu \mathrm{m}$ on an automatic microtome (Leica, RM2165, USA), mounted on histological slides and incubated at $60^{\circ} \mathrm{C}$. The sections were then deparaffinized and stained 
according to the Hematoxilin and Eosin (HE) technique [31].

\subsection{Statistical Analysis}

Statistical analysis was performed using GraphPad Prism 5 software (GraphPad, CA, USA), and statistical significance of differences between groups was determined using unpaired one-way ANOVA. Means were compared using Tukey's multiple comparison tests. Regression analysis was used to examine data obtained and to infer relationships between a dependent variable and an independent variable. Comparisons were considered either non significant (ns) or significant at ${ }^{*} \mathrm{p}<0.05$.

\section{Results}

\subsection{Growth Curve and Cell Viability}

The DFSCs cultured were photographed for morphologic analysis. During the cell culture, one can observe the rapid increase in the number of DFSCs and the morphological similarity of stem cells with fibroblast-like characteristics (Figure 1). It is possible to observe debris and cell death in the after 20 days of culture. The cells there show a lack of regular morphologic characteristics and presence of cellular fragments in supernatant, nuclear disorder, the formation of apoptotic bodies, and depolarization of the existing filament cytoskeleton.

Growth curves were determined to ensure that cells used in experiments were within the exponential growth phase. Cell proliferation was assessed by monitoring the conversion of MTT to formazan. Regarding the growth curve of DF cells, it can be seen that there is an increase in cell number of approximately $150 \%$ by the 10 th day of culture after this period of cell proliferation decreased significantly. Cell viability remained close to $95 \%$ on the 12th day of culture. After this period, there was a near $20 \%$ decline in the 15th day, and this situation continued until the 25th day of culture but in smaller percentages (Figure 2(A)).

Shown in Figure 2(A), it can be said that until the 10th day of culture, cell rate of cells that are not viable is

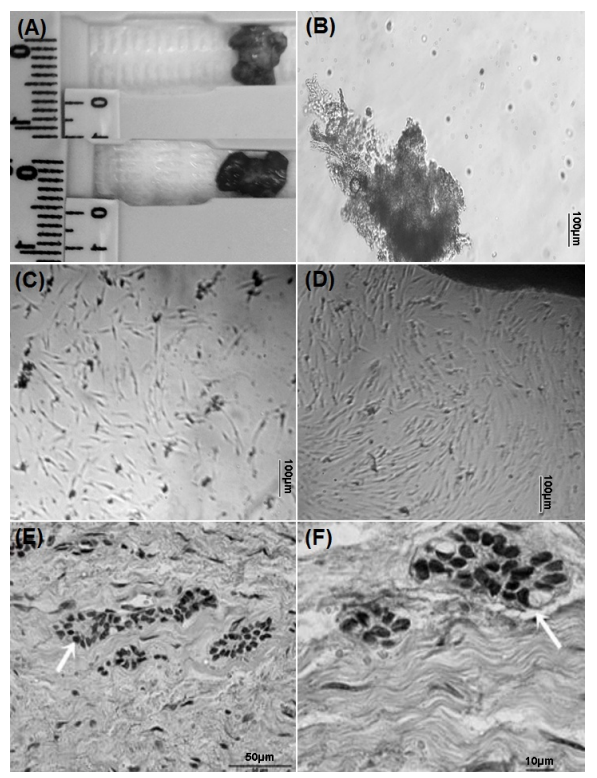

Figure 1. Dental follicle, cell culture, and histopathological analysis. (A) Surgical sample of DF of the third molars; (B) Microscopic image of DFSCs in the start of culture, showing cell detachment; (C) Photomicrograph in inverted microscope showing that primary culture of DFSCs represents a typical cell colony originated from a single progenitor cell. The morphology of the cells within the colony is fibroblast-like on the 6th day; (D) Photomicrograph in inverted microscope showing primary culture of DFSCs at 10th day of culture; (E) (F) Histological analysis of DF was performed using hematoxylin and eosin staining. The DFSCs are grouped. A dense, fibrous layer formed by mesodermal tissue surrounding the enamel. Their cells eventually migrate to the outer surface of the newly formed dentin in the tooth and the root to give rise to cementoblasts who deposited cementum in the root in development to fibroblasts of the periodontal ligament and osteoblasts of the of alveolar bone in development. The mesenchyme condenses and forms the dental follicle, as emphasized by the arrows, which will produce the periodontium. Highlight islets odontogenic epithelial embryonic tissue. 


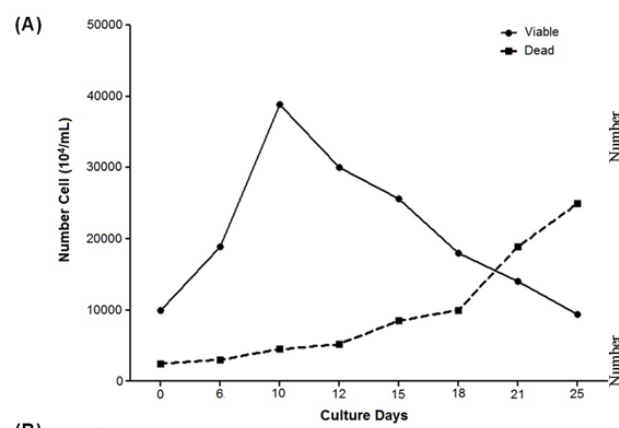

(B)
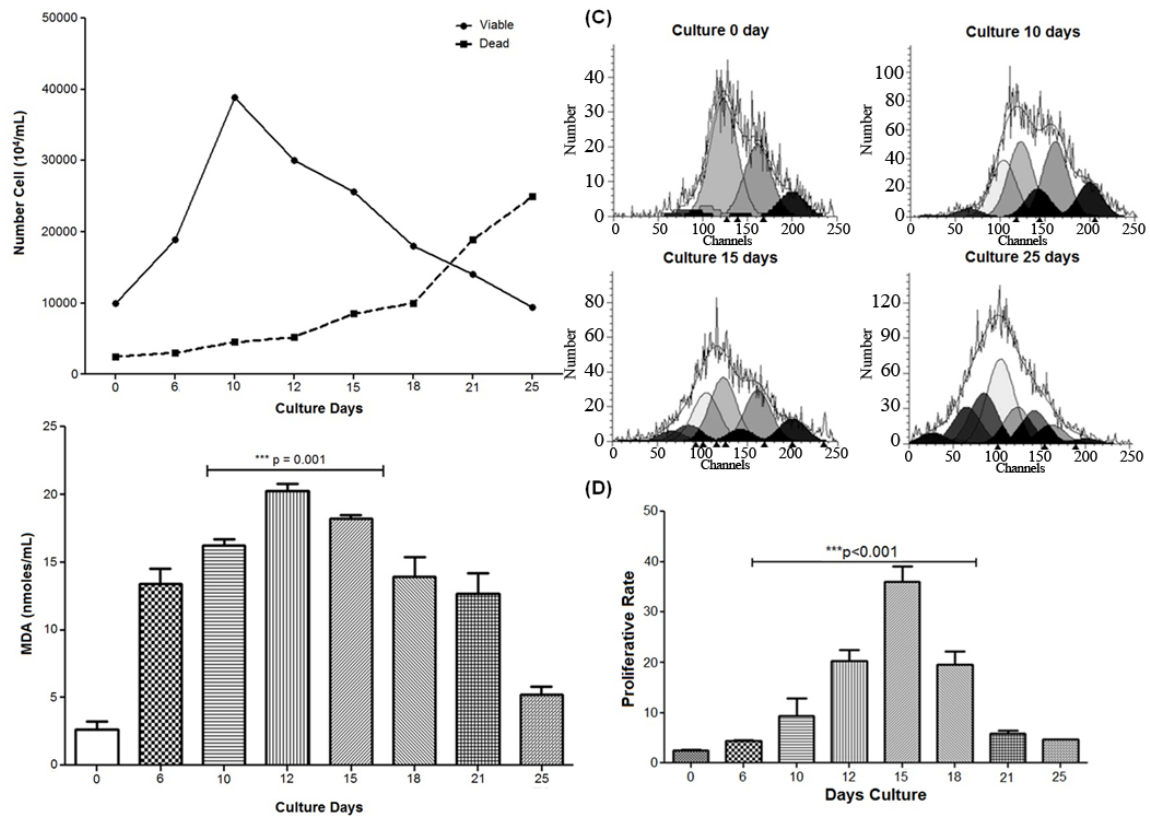

(D)

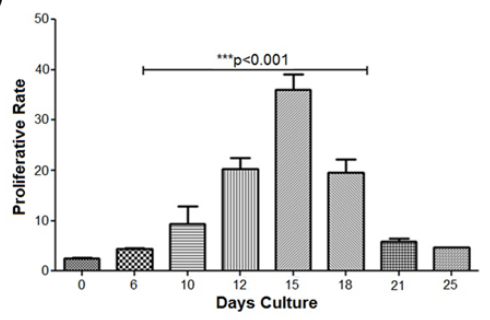

Figure 2. Growth curve, lipid peroxidation, and cell division rates of DFSCs. (A) Growth curve DFSCs during 25 days of culture. $\mathrm{N}=3$; (B) Graph showing the amount of thiobarbituric acid reactive substances MDA forrmed in the supernatant of DFSCs. Test nonparametric variance ANOVA followed by Tukey multiple test considering significant ${ }^{*} \mathrm{p}<0.001$; (C) Histograms represent the flow cytometric analyses of CFSE-DA of the DFSCs; (D) Graph showing mean proliferative rates of DF cells during 25 days of culture using CFSE-DA.

low; after this period, there is an inversion where the number of cells falls drastically while the rate of nonviable cells increases significantly.

\subsection{Cell Division Rates of DFSCs}

Cell division is characterized by sequential halving of CFSE-DA fluorescence, generating equally spaced peaks on a logarithmic scale; peaks indicate the division cycle number. Similar results of MTT colorimetric assay were obtained using CFSE-DA methodology, which accurately confirmed significant rate of proliferation of DF cells. Results of cell division rates show a significant increase between 6th and 15th day of culture. From 15th until 18th day, the decrease in proliferative index drops by half, and the proliferative index continues to decline, but in a lower value, to the 25th day of culture (Figure 2(C) and Figure 2(D)).

\subsection{Lipid Peroxidation}

We also evaluated whether the proliferative effects in DF cells correlate with a change in the status of oxidative stress; by production of lipid peroxides through the formation of malondialdehyde (MDA). The results of lipid peroxidation in DFSCs shown in culture spontaneously produce about $13 \mathrm{nmoles} / \mathrm{ml} \mathrm{MDA}$ at the start of culture. This production significantly increases gradually until the 12th day of culture and begins a decline that lasted until the 15th day of culture. In DFSCs, MDA production was 5 times higher than culture initiation, after 12 days of culture. These results demonstrate that growth could change the oxidative stress status of DFSCs undifferentiated (Figure 2(B)).

\subsection{Cell Cycle Phases Analysis}

The study of cell cycle phases illustrates the distribution of DF cells that were in G0/G1, S, and G2/M phases, which exhibited DNA fragmentation. The evaluation of cell cycle of the DFSCs during the 25 days of culture demonstrated a $70 \%$ accumulation of cells in G0/G1 phase and a small percentage of approximately $25 \%$ of cells in S and G2/M phases until the 12th day. After that, there was a significant increase in the population of 
cells in G2/M between the 15th and 18th day of culture. Subsequently, there was a gradual decrease in the population of cells in S and G2/M phases; therefore was an increase in G0/G1 until the 25th day of culture (Figure 3(A) and Figure 3(B)).

\subsection{Measurement of Mitochondrial Transmembrane Potential ( $\Delta \psi \mathrm{m})$}

The mitochondrial transmembrane potential $(\Delta \psi \mathrm{m})$ is essential to maintain the physiological function of the respiratory chain to generate energy. In the DFSCs, mitochondrial potential showed no significant difference in the period from the 0th to 25th day of culture (Figure 3(C) and Figure 3(D)).

\subsection{Cell Expression Markers Mesenchymal Stem Cell}

In the present study, 08 samples were obtained from the dental follicle, cultured until the 25th day, and subsequently frozen in liquid nitrogen. After thawing, viability was maintained at a mean of $92 \%$ and exhibited the same morphological characteristics of the fibroblast-like. Cell surface marker profiles obtained by flow cytometry revealed that cell lines were negative for HLA-DR and positive for CD90, CD44, and CD105 markers at 12th and 25th days of culture and that there was no significant difference between culture passages. The results are shown in dot plots by cytometric analyses (Figure 4(A)) and media and standard deviation at 12th and 25th days of culture (Figure 4(B)).

\subsection{Expression of Bcl-2, Cyclin D1, Cytochrome-c, p21 and PCNA by Flow Cytometry}

The markers' expression of control, progression, and cell proliferation was determined by flow cytometry and showed no significant difference during the period of cultivation of the cells of the dental follicle. The expres-

(A)
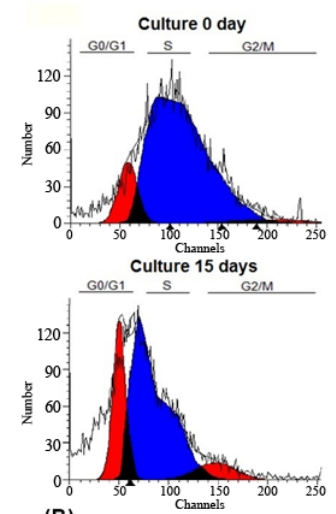

(B)
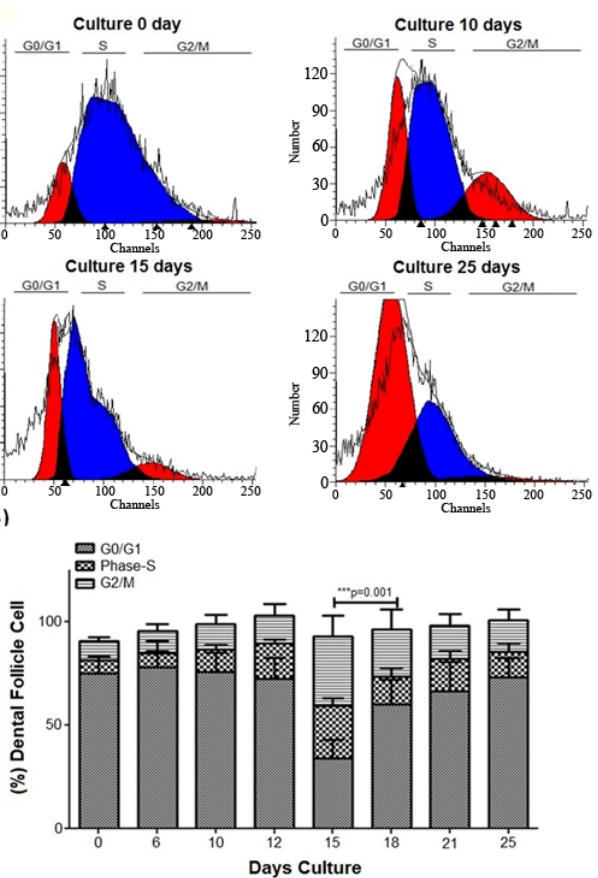

(C)
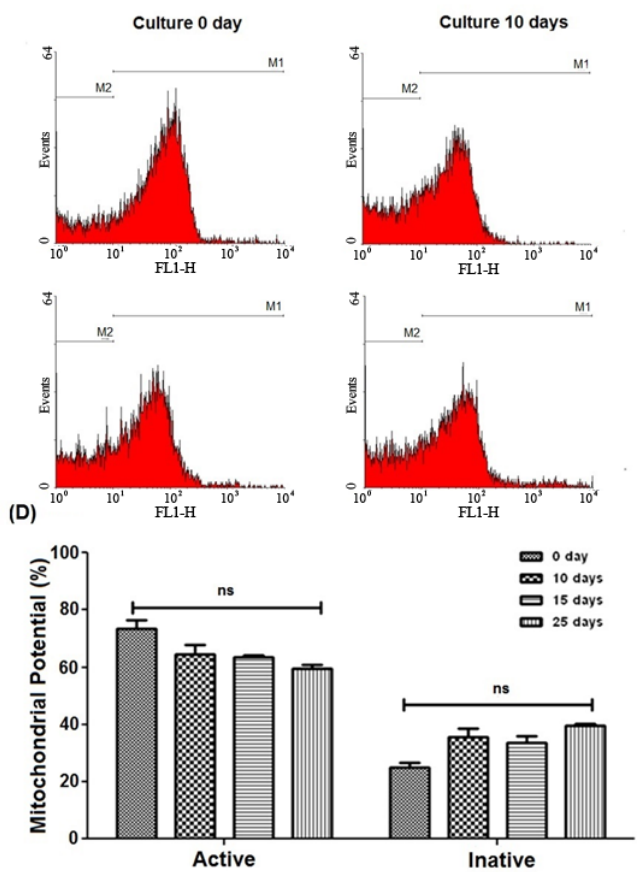

Figure 3. Cell cycle phases and mitochondrial transmembrane potential ( $\Delta \psi \mathrm{m})$ in DFSCs culture. (A) Histograms represent the flow cytometric analyses of cell cycle from DFSCs; (B) Graph showing the mean percent of populations cells in G2/M, G0/G1, and S phases in different days of culture; (C) Representative histograms obtained from FACS analysis of DFSCs labelling with Rho123 (M1-Mitochondria population active) and (M2-Mitochondria population inative). The figure shows an overlay of histograms from samples analyzed by flow cytometry; (D) Graph showing mitochondrial transmembrane potential of DFSCs during 25 days of culture. The data are the means \pm SD ${ }^{* * *}$ p $<0.001$ from at least three independent experiments. 

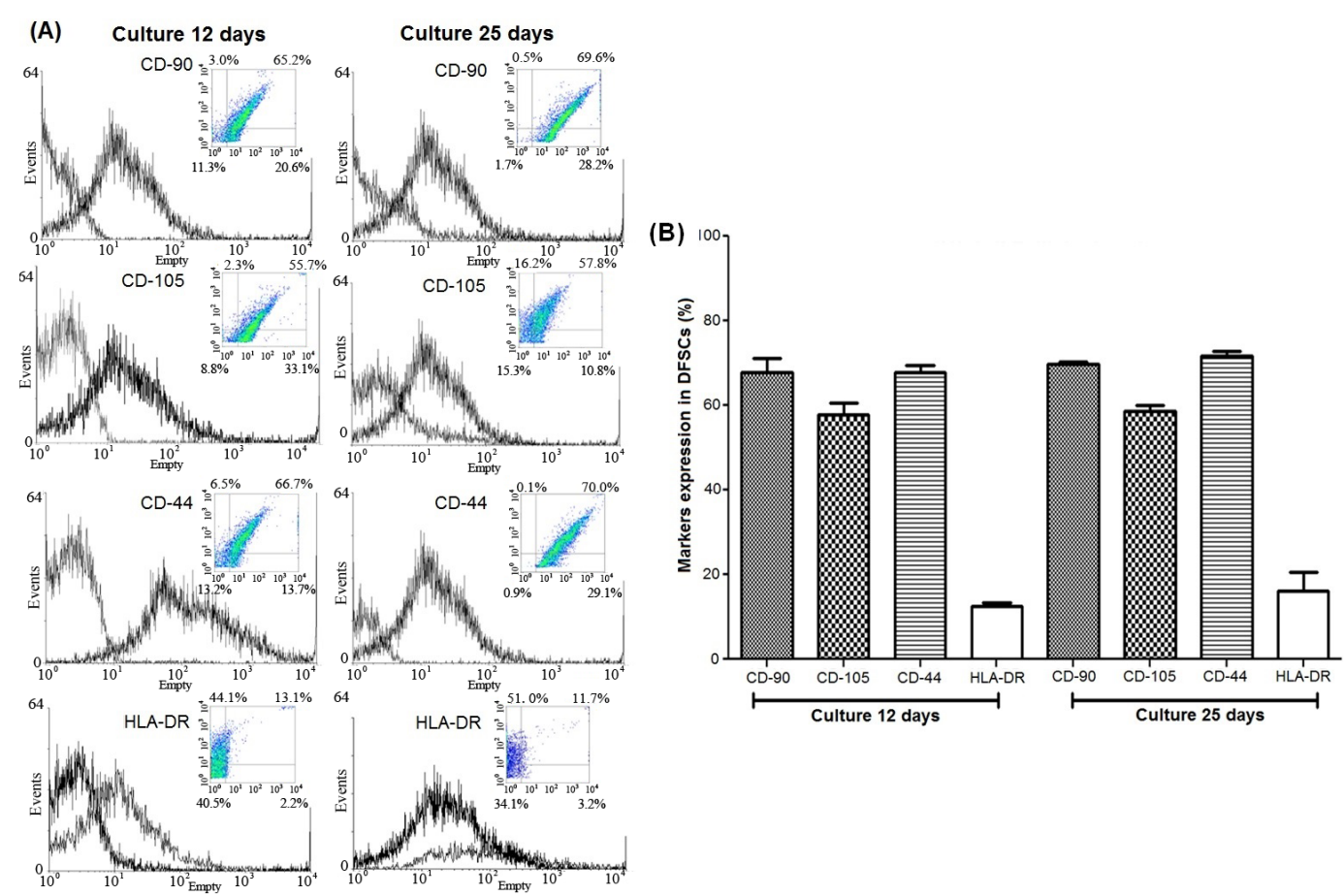

Figure 4. Expression markers mesenchymal A). Histograms and dot plots represent the flow cytometric analyses cell surface antigen after 12th and 25th DF culture days. B) Statistical analysis by expression markers mesenchymal stem cells in DF. Mean \pm standart deviation of markers in culture 12th and 25th culture days. No significant difference was observed in DFSCs (Unpaired one-way ANOVA).

sion of p21 protein, involved in the regulation of the cell cycle, showed a significant increase from the 15th to 25th days of culture (Figure 5).

\section{Discussion}

In dentistry, the experiments have been directed to the use of cell therapy in the regeneration of oral tissues and for collection, isolation, culture, and characterization of stem cells derived from the oral tissues [32]-[34]. Some studies suggest that stem cells obtained from deciduous teeth have a greater potential for proliferation and regeneration than permanent teeth [35].

Normal stem cells are defined by an extensive capacity for self-renewal and by their ability to undergo a broad range of differentiation. In the present study, it was revealed that DFSCs presented a significantly higher percentage of cells in S + G2/M phases by 15 days of culture when compared with cells at the start of culture, indicating that DF culture enhanced the proliferation response in vitro.

The experiments described here were designed to provide knowledge about the response in the proliferation of undifferentiated DFSC third molars following culture conditions. In the literature there is no paper that describes the patterns of growth curve, lipid production, markers expression, and cell viability of DFSCs. The MTT assay, cell cycle phases, and CSFE were performed to investigate DFSCs' potential in culture. The number of DFSCs following culture was estimated after 25 days. Nonviable cells' significance was observed by culture. Cell cycle distributions were analyzed by flow cytometry in the form of proliferation rate.

As well as in a study by Schiraldi et al. (2012), [36] on the migratory capacity of stem cells from pulp and dental follicle, we also observed that stem cells from the dental follicle followed a circular motion and explored the local environment. Huang et al. (2006) [37] found that 1 to 2 weeks after the beginning of culture, the cell colonies contained fibroblast-like shape, and this shape was retained after 5 or more passageways.

As it can be seen from Figure 2(A), the growth curve plotted for either cell indicated that the DFSCs from the third molar were the first that reached the plateau phase between the 10th day and declined after 15 days of culture. According to this curve, the lag phase tended to be about 5 days for either culture, meaning that cells 


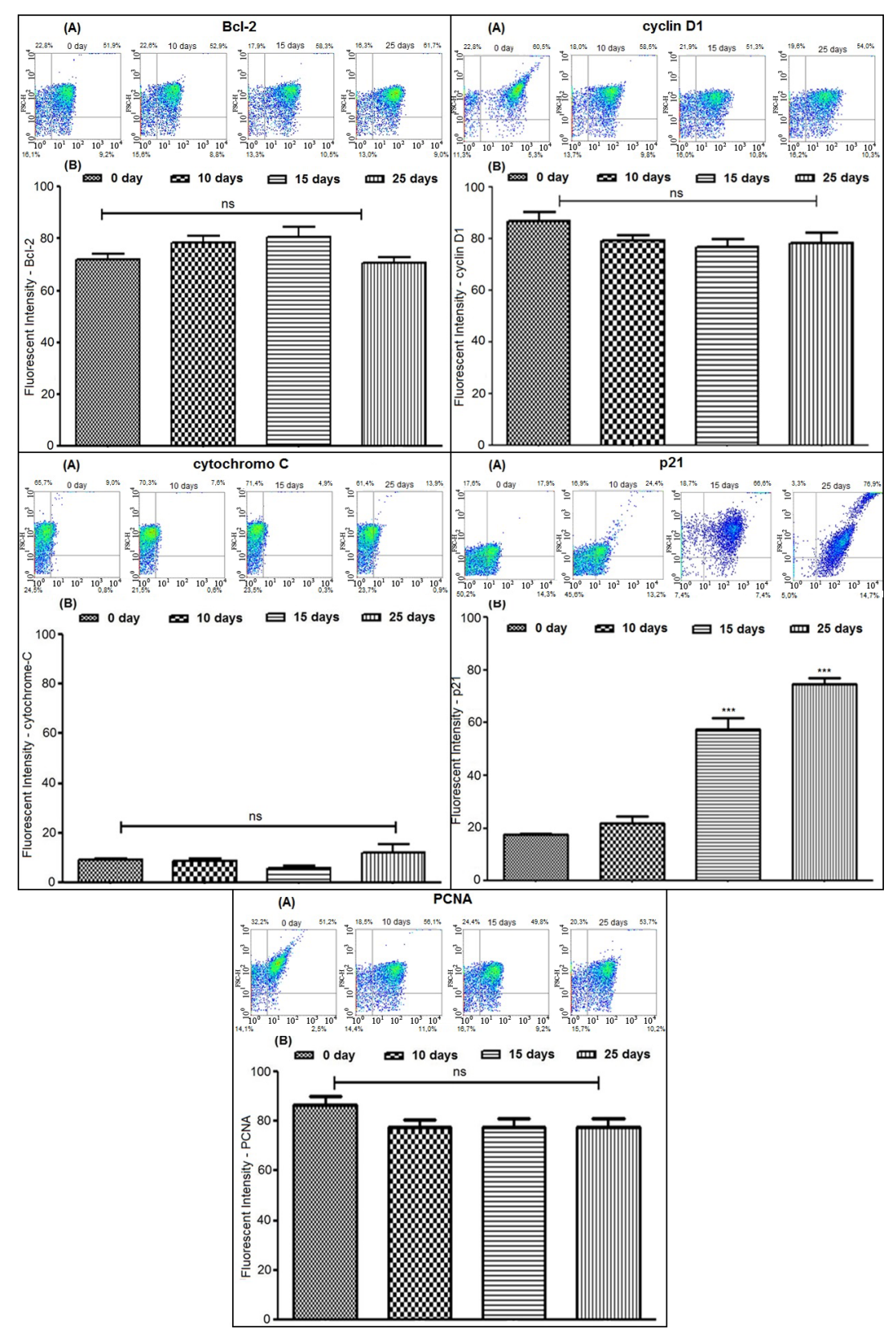

Figure 5. The expression of BCL-2, cyclin D1, cytochrome-C, PCNA, and p21 was detected through fluorescence intensity analysis by FACS. (A) Dot plots represent the flow cytometric analyses expression markers during 25 days of culture; (B) Graph showing expression markers during 25 days of culture. The data are the means \pm SD ${ }^{* * *} \mathrm{p}<0.001$ from at least three independent experiments.

started to proliferate two days after being plated. The lag phase was considered to be the adaptation phase to culture conditions.

The proliferation index, defined as the percentage of proliferating cells in a population, is a very important parameter to evaluate the in-vitro stimulation potency of growth factors and the antiproliferative activity of factor growth or response extrinsic in culture cells [38]. Under unfavorable conditions such as nutrient and growth factor deprivation or high cell density, cells can also reversibly withdraw from the cell cycle and enter into a resting non-proliferative gap. Cultured mammalian cells have been widely used to examine the molecular mechanisms of the cell cycle and its pathways of regulation. The importance of these studies lies in the under- 
standing of normal cell behavior as well as deregulation effects in other diseases like transformation cells, responsible for growth tumor, but also for predicting cellular responses to several agents used in therapy, since many of them are cell cycle phase-specific [39]. The DNA fragmentation that ensues is one hallmark of apoptotic cell death. We used in this study the simplest and most basic flow cytometric method to assess cell phase distribution and to measure the amount of DNA per cell by using DNA intercalating agents such as propidium iodide (PI).

A number of the crucial events in apoptosis commence in the mitochondria. These organelles are required for efficient energy metabolism, production of membrane lipids, and cell growth but are also the primary determinants of cellular life or death. These include the activation of the family of cysteine proteases known as caspases, e.g. cytochrome c, and disruption of the electron transport chain leading to changes in oxidative phosphorylation and ATP synthesis. Other mechanisms include loss of mitochondrial membrane potential, variations in redox potential, and involvement of pro- and anti-apoptotic family proteins, e.g. Bcl-2 [40].

Oxidative stress that occurs in the cells, because of an imbalance between the pro oxidant/antioxidant systems, causes injury to biomolecules such as nucleic acids, proteins, structural carbohydrates, and lipids [41]. Both of the oxidant and antioxidant species are very important for normal metabolism, signal transduction, and regulation of cellular functions. Currently, the role of ROS is accepted in human pathology. The primary effect of oxidative stress is localized and reversible depending on the level and intensity of antioxidants. The physiological generation of ROS acts as a marker of secondary messengers that influence the proliferation, cell differentiation, and apoptosis, in addition to regulating the expression of genes. The accumulation of ROS is common in senescent cells. ROS have been related to the regulation of stem cell pluripotency, proliferation, and differentiation, besides being a critical factor which regulates the quiescent state of MSC [42]-[45]. The results obtained in this study showed that MDA levels obtained during the growth of stem cells from dental follicle of third molars had a significant increase between the 6th and 12th day of culture, accompanied by a high rate of cell growth. However, after this time there was a drastic reduction in the number of cells, and it was accompanied by increased mortality and reduced production of MDA. Chatzivasileiou et al. (2013) [46] have made a study with dental follicle stem cells and showed that cells derived from the dental follicle were significantly higher ins colony-forming efficiency compared to colony-forming efficiency of marrow bone stem cell. There are two sources of cellular oxidants, reactive oxygen and nitrogen species that can be generated from physiological processes as well as exogenous sources (xenobiotic interaction). When the antioxidant control mechanisms are overrun, the cellular redox potential shifts toward oxidative stress. As a consequence, the potential for damage to cellular nucleic acids, lipids, or proteins increases [47].

This study showed DFSCs were positive for specific markers of mesenchymal stem cells, CD-44, CD-90, and CD-105, indicating that those cells are from mesenchymal sources. The DFSCs are negative for marker of hematopoietic lineage, HLA-DR. The results of this study in relation to markers of MSCs are compatible with other studies in the literature [48] [49].

Cell cycle is tightly controlled by many regulatory mechanisms that either permit or restrain its progression. The signaling pathways that control these processes are central to the functioning of all multi-cellular life, and any defects in cell cycle control may lead to chromosome alterations, loss of cellular growth control, and the induction of cell transformation. The cell cycle is maintained by phosphorylation and dephosphorylation of the cell cycle gene products by cyclin/Cdk complexes, the last being a group of proteins present at the interphase cell, expressed in proliferating cells. The D-type cyclins are the first cyclins to be induced as G0 cells are stimulated to enter the cell cycle. Overexpression of D or E type cyclins can contract Gl phase, decrease cell size, and reduce the dependency of the cell on response to extracellular mitogenic [50].

Our study of cyclin D1 and Bcl-2 expression was not significant following DFSCs culture. Cyclin D1 was also demonstrated to physically interact with 2 other proteins involved in DNA repair, PCNA, and replication factor C. PCNA is a member of the so-called DNA sliding clamp family. The essential function of providing replicative polymerases with the high processivity is required to duplicate an entire genome. DNA damage, senescence, or differentiation of cells through either p53 dependent or independent pathways induces the expression of the p21 protein, which blocks progression from G1 to S phase of the cell cycle [51]-[53]. The results suggest that PCNA is an essential mediator of the regulatory action of p21, being responsible for the initial maintenance of the state of differentiation of DFSCs. Cyclin D1 can also override G1 phase checkpoint arrest in response to DNA damage. 


\section{Conclusion}

We concluded that DFSCs obtained from dental follicle third molars after the culture maintained undifferentiated potential with the presence of stem cell precursors. There was no significant change in the expression of mesenchymal markers and progression control of cell cycle DFSCs in culture. There was an increased production of lipid peroxidation between the 6th and 12th days of culture. This increase is related to the increased numbers of stem cells that also occurs during this period. Then, there is a significant decline in the production of lipid peroxidation and the number of cells, which is accompanied by an increase in cell mortality. This means that free radicals may influence cell death. To the best of our knowledge, there is very limited information regarding in-vitro growth response and culture needs of the DFSCs. Having the growth characteristics as well as culture requirements of the cells could be of great importance for those who specially are involved in stem cell investigations with the aim of remodeling and regenerating tissue.

\section{Acknowledgements}

Dental surgeon Rodrigo de Andrade Rodrigues for collected samples patients.

\section{References}

[1] Secco, M., Zucconi, E., Vieira, N.M., Fogac, L.L.Q., Cerqueira, A., Carvalho, M.D.F., Jazedje, T., Okamoto, O.K., Muotri, A.R. and Zatz, M. (2008) Multipotent Stem Cells from Umbilical Cord: Cord Is Richer than Blood! Stem Cells, 26, 146-150. http://dx.doi.org/10.1634/stemcells.2007-0381

[2] Cmielova, J., Havelek, R., Kohlerova, R., Soukup, T., Bruckova, L., Suchanek, J., Vavrova, J., Mokry, J. and Rezacova, M. (2013) The Effect of ATM Kinase Inhibition on the Initial Response of Human Dental Pulp and Periodontal Ligament Mesenchymal Stem Cells to Ionizing Radiation. International Journal of Radiation Biology, 89, 501-511. http://dx.doi.org/10.3109/09553002.2013.775530

[3] Honda, M.J., Imaizumi, M., Tsuchiya, S. and Morsczeck, C. (2010) Dental Follicle Stem Cells and Tissue Engineering. Journal of Oral Science, 52, 541-552. http://dx.doi.org/10.2334/josnusd.52.541

[4] Kim, J.C., Park, J.C., Kim, S.H., Im, G.I., Kim, B.S., Lee, J.B., Choi, E.Y., Song, J.S., Cho, K.S. and Kim, S.C. (2013) Treatment of FGF-2 on Stem Cells from Inflamed Dentalpulp Tissue from Human Deciduous Teeth. Oral Diseases, 20. http://dx.doi.org/10.1111/odi.12089

[5] Chatakun, P., Núñez-Toldrà, R., Díaz López, E.J., Gil-Recio, C., Martínez-Sarrà, E., Hernández-Alfaro, F., FerrésPadró, E., Giner-Tarrida, L. and Atari, M. (2013) The Effect of Five Proteins on Stem Cells Used for Osteoblast Differentiation and Proliferation: A Current Review of the Literature. Cellular and Molecular Life Sciences, 71, 113-142. http://dx.doi.org/10.1007/s00018-013-1326-0

[6] Estrela, C., Alencar, A.H.G., Kitten, G.T., Vencio, E.F. and Gava, E. (2011) Mesenchymal Stem Cells in the Dental Tissues: Perspectives for Tissue Regeneration. Brazilian Dental Journal, 22, 91-98. http://dx.doi.org/10.1590/S0103-64402011000200001

[7] Leprince, J.G., Zeitlin, B.D., Tolar, M. and Peters, O.A. (2012) Interactions between Immune System and Mesenchymal Stem Cells in Dental Pulp and Periapical Tissues. International Endodontic Journal, 45, 689-701. http://dx.doi.org/10.1111/j.1365-2591.2012.02028.x

[8] Rad, M.R., Wise, G.E., Brooks, H., Flanagan, M.B. and Yao, S. (2013) Activation of Proliferation and Differentiation of Dental Follicle Stem Cells (DFSCs) by Heat Stress. Cell Proliferation, 46, 58-66. http://dx.doi.org/10.1111/cpr.12004

[9] Mori, G., Ballini, A., Carbone, C., Oranger, A., Brunetti, G., Di Benedetto, A., Rapone, B., Cantore, S., Di Comite, M., Colucci, S., Grano, M. and Grassi, F.R. (2012) Osteogenic Differentiation of Dental Follicle Stem Cells. International Journal of Medical Sciences, 9, 480-487. http://dx.doi.org/10.7150/ijms.4583

[10] Luan, X., Ito, Y., Dangaria, S. and Diekwisch, T.G.H. (2006) Dental Follicle Progenitor Cell Heterogeneity in the Developing Mouse Periodontium. Stem Cells and Development, 15, 595-608. http://dx.doi.org/10.1089/scd.2006.15.595

[11] Huang, G.T.J., Gronthos, S. and Shi, S. (2009) Mesenchymal Stem Cells Derived from Dental Tissues vs. Those from Other Sources: Their Biology and Role in Regenerative Medicine. Journal of Dental Research, 88, 792-806. http://dx.doi.org/10.1177/0022034509340867

[12] Viale-Bouroncle, S., Buergers, R., Morsczeck, C. and Gosau, M. (2013) $\beta$-Tricalcium Phosphate Induces Apoptosis on Dental Follicle Cells. Calcified Tissue International, 92, 412-417. http://dx.doi.org/10.1007/s00223-012-9694-2

[13] Yalvac, M.E., Ramazanoglu, M., Gumru, O.Z., Sahin, F., Palotás, A. and Rizvanov, A.A. (2009) Comparison and Optimisation of Transfection of Human Dental Follicle Cells, a Novel Source of Stem Cells, with Different Chemical Me- 
thods and Electroporation. Neurochemical Research, 34, 1272-1277. http://dx.doi.org/10.1007/s11064-008-9905-4

[14] Guerrero, M.E., Botetano, R., Beltran, J., Horner, K. and Jacobs, R. (2013) Can Preoperative Imaging Help to Predict Postoperative Outcome after Wisdom Tooth Removal? A Randomized Controlled Trial Using Panoramic Radiography versus Cone-Beam CT. Clinical Oral Investigations, 18, 335-342. http://dx.doi.org/10.1007/s00784-013-0971-x

[15] Şimşek-Kaya, G., Özbek, E., Kalkan, Y., Yapıcı, G., Dayı, E. and Demirci, T. (2011) Soft Tissue Pathosis Associated with Asymptomatic Impacted Lower Third Molars. Medicina Oral Patologia Oral y Cirugia Bucal, 16, 924-931. http://dx.doi.org/doi:10.4317/medoral.17128

[16] Hasegawa, T., Ri, S., Shigeta, T., Akashi, M., Imai, Y., Kakei, Y., Shibuya, Y. and Komori, T. (2013) Risk Factors Associated with Inferior Alveolar Nerve Injury after Extraction of the Mandibular Third Molar-A Comparative Study of Preoperative Images by Panoramic Radiography and Computed Tomography. International Journal of Oral and Maxillofacial Surgery, 42, 843-851. http://dx.doi.org/10.1016/j.ijom.2013.01.023

[17] Özer, N., Üçem, F., Saruhanoğlu, A., Yilmaz, S. and Tanyeri, H. (2013) Removal of a Maxillary Third Molar Displaced into Pterygopalatine Fossa via Intraoral Approach. Case Reports in Dentistry, 2013, Article ID: 392148. http://dx.doi.org/10.1155/2013/392148

[18] Blanchetot, C. and Boonstra, J. (2008) The ROS-NOX Connection in Cancer and Angiogenesis. Critical Reviews in Eukaryotic Gene Expression, 18, 35-45. http://dx.doi.org/10.1615/CritRevEukarGeneExpr.v18.i1.30

[19] Shi, X., Zhang, Y., Zheng, J. and Pan, J. (2012) Reactive Oxygen Species in Cancer Stem Cells. Antioxidants \& Redox Signaling, 16, 1215-1228. http://dx.doi.org/10.1089/ars.2012.4529

[20] Liang, C.H., Chan, L.P., Chou, T.H., Chiang, F.Y., Yen, C.M., Chen, P.J., Ding, H.Y. and Lin, R.J. (2013) Brazilein from Caesalpinia sappan L. Antioxidant Inhibits Adipocyte Differentiation and Induces Apoptosis through Caspase-3 Activity and Anthelmintic Activities against Hymenolepis nana and Anisakis simplex. Evidence-Based Complementary and Alternative Medicine, 2013, Article ID: 864892. http://dx.doi.org/10.1155/2013/864892

[21] Tekin, U., Güven, O. and Kurku, H. (2011) Malondialdehyde Levels in Dental Follicles of Asymptomatic Impacted Third Molars. Journal of Oral and Maxillofacial Surgery, 69, 1291-1294. http://dx.doi.org/10.1016/j.joms.2010.07.011

[22] Le Belle, J.E., Orozco, N.M., Paucar, A.A., Saxe, J.P., Mottahedeh, J., Pyle, A.D., Wu, H. and Kornblum, H.I. (2011) Proliferative Neural Stem Cells Have High Endogenous ROS Levels That Regulate Self-Renewal and Neurogenesis in a PI3K/Akt-Dependant Manner. Cell Stem Cell, 8, 59-71. http://dx.doi.org/10.1016/j.stem.2010.11.028

[23] Hsieh, C., Hernández-Ledesma, B. and de Lumen, B.O. (2011) Cell Proliferation Inhibitory and Apoptosis-Inducing Properties of Anacardic Acid and Lunasin in Human Breast Cancer MDA-MB-231 Cells. Food Chemistry, 125, 630636. http://dx.doi.org/10.1016/j.foodchem.2010.09.051

[24] Mosmann, T. (1983) Rapid Colorimetric Assay for Cellular Growth and Survival: Application to Proliferation and Cytoxicity Assays. Journal of Immunological Methods, 65, 55-63. http://dx.doi.org/10.1016/0022-1759(83)90303-4

[25] Milovanova, T., Popma, S., Cherian, S., Moore, J.S. and Rossman, M.D. (2004) Flow Cytometric Test for Beryllium Sensitivity. Cytometry Part B: Clinical Cytometry, 60, 23-30. http://dx.doi.org/10.1002/cyto.b.20015

[26] Bernard, S., Pujo-Menjouet, L. and Mackey, M.C. (2003) Analysis of Cell Kinetics Using a Cell Division Marker: Mathematical Modeling of Experimental Data. Biophysical Journal, 84, 3414-3424. http://dx.doi.org/10.1016/S0006-3495(03)70063-0

[27] Lyons, A.B. (2000) Analysing Cell Division in Vivo and in Vitro Using Flow Cytometric Measurement of CFSE Dye Dilution. Journal of Immunological Methods, 243, 147-154. http://dx.doi.org/10.1016/S0022-1759(00)00231-3

[28] Lyons, A.B., Hasbold, J. and Hodgkin, P.D. (2001) Flow Cytometric Analysis of Cell Division History Using Dilution of Carboxyfluorescein Diacetate Succinimidyl Ester, a Stably Integrated fluorescent Probe. Methods in Cell Biology, 63, 375-398. http://dx.doi.org/10.1016/S0091-679X(01)63021-8

[29] Wells, A.D., Gudmundsdottir, H. and Turka, L.A. (1997) Following the Fate of Individual T Cells throughout Activation and Clonal Expansion. Signals from T Cell Receptor and CD28 Differentially Regulate the Induction and Duration of a Proliferative Response. The Journal of Clinical Investigation, 100, 3173-3183. http://dx.doi.org/10.1172/jci119873

[30] Ohkawa, H., Ohishi, N. and Yagi, K. (1979) Assay for Lipid Peroxides in Animal Tissues by Thiobarbituric Acid Reaction. Analytical Biochemistry, 95, 351-358. http://dx.doi.org/10.1016/0003-2697(79)90738-3

[31] Fischer, A.H., Jacobson, K.A., Rose, J. and Zeller, R. (2013) Hematoxylin and Eosin Staining of Tissue and Cell Sections. Cold Spring Harbor Protocols. http://dx.doi.org/10.1101/pdb.prot4986

[32] Atari, M., Barajas, M., Hernández-Alfaro, F., Gil, C., Fabregat, M., Padró, E.F., Giner, L. and Casals, N. (2011) Isolation of Pluripotent Stem Cells from Human Third Molar Dental Pulp. Histology and Histopathology, 26, 1057-1070.

[33] Janebodin, K., Horst, O.V., Ieronimakis, N., Balasundaram, G., Reesukuma, K., Pratumvinit, B. and Reyes, M. (2011) Isolation and Characterization of Neural Crest-Derived Stem Cells from Dental Pulp of Neonatal Mice. PLoS ONE, 6, e27526. http://dx.doi.org/10.1371/journal.pone.0027526 
[34] Tirino, V., Paino, F., De Rosa, A. and Papaccio, G. (2012) Identification, Isolation, Characterization, and Banking of Human Dental Pulp Stem Cells. Methods in Molecular Biology, 879, 443-463. http://dx.doi.org/10.1007/978-1-61779-815-3_26

[35] Nakamura, S., Yamada, Y., Katagiri, W., Sugito, T., Ito, K. and Ueda, M. (2009) Stem Cell Proliferation Pathways Comparison between Human Exfoliated Deciduous Teeth and Dental Pulp Stem Cells by Gene Expression Profile from Promising Dental Pulp. Journal of Endodontics, 35, 1536-1542. http://dx.doi.org/10.1016/j.joen.2009.07.024

[36] Schiraldi, C., Stellavato, A., D’Agostino, A., Tirino, V., d’Aquino, R., Woloszyk, A., De Rosa, A., Laino, L., Papaccio, G. and Mitsiadis, T.A. (2012) Fighting for Territories: Time-Lapse Analysis of Dental Pulp and Dental Follicle Stem Cells in Co-Culture Reveals Specific Migratory Capabilities. European Cells and Materials, 24, 426-440.

[37] Huang, G.T.J., Sonoyama, W., Chen, J. and Park, S.H. (2006) In Vitro Characterization of Human Dental Pulp Cells: Various Isolation Methods and Culturing Environments. Cell and Tissue Research, 324, 225-236. http://dx.doi.org/10.1007/s00441-005-0117-9

[38] Gasparri, F., Mariani, M., Sola, F. and Galvani, A. (2004) Quantification of the Proliferation Index of Human Dermal Fibroblast Cultures with the ArrayScan ${ }^{\mathrm{TM}}$ High-Content Screening Reader. Journal of Biomolecular Screening, 9, 232243. http://dx.doi.org/10.1177/1087057103262836

[39] Bedolla, D.E., Kenig, S., Mitri, E., Ferraris, P., Marcello, A., Grencie, G. and Vaccari, L. (2013) Determination of Cell Cycle Phases in Live B16 Melanoma Cells Using IRMS. Analyst, 138, 4015-4021. http://dx.doi.org/10.1039/c3an00318c

[40] Kadenbach, B. (2012) Introduction to Mitochondrial Oxidative Phosphorylation. Advances in Experimental Medicine and Biology, 748, 1-11. http://dx.doi.org/10.1007/978-1-4614-3573-0_1

[41] Sies, H. and Cadenas, E. (1985) Oxidative Stress: Damage to Intact Cells and Organs. Philosophical Transactions of the Royal Society of London, Series B: Biological Sciences, 311, 617-631. http://dx.doi.org/10.1098/rstb.1985.0168

[42] Lazescu, A.V., Gruia, M.I., Anghel, R. and Glavan, D. (2013) Monitoring the Production of Reactive Oxygen Species in Experimental Melanoma. Journal of Medicine and Life, 6, 235-239.

[43] Jones, R.M., Luo, L., Ardita, C.S., Richardson, A.N., Kwon, Y.M., Mercante, J.W., Alam, A., Gates, C.L., Wu, H., Swanson, P.A., Lambeth, J.D., Denning, P.W. and Neish, A.S. (2013) Symbiotic Lactobacilli Stimulate Gut Epithelial Proliferation via Nox-Mediated Generation of Reactive Oxygen Species. EMBO Journal, 32, 3017-3028.

[44] Moazzen, H., Lu, X., Ma, N.L., Velenosi, T.J., Urquhart, B.L., Wisse, L.J., Groot, A.C.G. and Feng, Q. (2014) NAcetylcysteine Prevents Congenital Heart Defects Induced by Pregestational Diabetes. Cardiovascular Diabetology, 13, 46. http://dx.doi.org/10.1186/1475-2840-13-46

[45] Guida, M., Maraldi, T., Resca, E., Beretti, F., Zavatti, M., Bertoni, L., La Sala, G.B. and De Pol, A. (2013) Inhibition of Nuclear Nox4 Activity by Plumbagin: Effect on Proliferative Capacity in Human Amniotic Stem Cells. Oxidative Medicine and Cellular Longevity, 2013, Article ID: 680816. http://dx.doi.org/10.1155/2013/680816

[46] Chatzivasileiou, K., Lux, C.A., Steinhoff, G. and Lang, H. (2013) Dental Follicle Progenitor Cells Responses to Porphyromonas gingivalis LPS. Journal of Cellular and Molecular Medicine, 17, 766-773. http://dx.doi.org/10.1111/jcmm.12058

[47] Dayem, A.A., Choi, H.Y., Kim, J.H. and Cho, S.G. (2010) Role of Oxidative Stress in Stem, Cancer, and Cancer Stem Cells. Cancers, 2, 859-884. http://dx.doi.org/10.3390/cancers2020859

[48] Luan, X., Ito, Y., Dangaria, S. and Diekwisch, T.G.H. (2006) Dental Follicle Progenitor Cell Heterogeneity in the Developing Mouse Periodontium. Stem Cells and Development, 15, 595-608. http://dx.doi.org/10.1089/scd.2006.15.595

[49] Park, B.W., Kang, E.J., Byun, J.H., Son, M.G., Kim, H.J., Hah, Y.S., Kim, T.H., Kumar, B.M., Ock, S.A. and Rho, G.J. (2012) In Vitro and in Vivo Osteogenesis of Human Mesenchymal Stem Cells Derived from Skin, Bone Marrow and Dental Follicle Tissues. Differentiation, 83, 249-259. http://dx.doi.org/10.1016/j.diff.2012.02.008

[50] Agami, R. and Bernards, R. (2000) Distinct Initiation and Maintenance Mechanisms Cooperate to Induce G1 Cell Cycle Arrest in Response to DNA Damage. Cell, 102, 55-66. http://dx.doi.org/10.1016/S0092-8674(00)00010-6

[51] Matsuoka, S., Yamaguchi, M. and Matsukage, A. (1994) D-Type Cyclin-Binding Regions of Proliferating Cell Nuclear Antigen. Journal of Biological Chemistry, 269, 11030-11036.

[52] Xiong, Y., Zhang, H. and Beach, D. (1992) D Type Cyclins Associate with Multiple Protein Kinases and the DNA Replication and Repair Factor PCNA. Cell, 71, 505-514. http://dx.doi.org/10.1016/0092-8674(92)90518-H

[53] van der Kuip, H., Carius, B., Haque, S.J., Williams, B.R., Huber, C. and Fischer, T. (1999) The DNA-Binding Subunit p140 of Replication Factor C Is Upregulated in Cycling Cells and Associates with G1 Phase Cell Cycle Regulatory Proteins. Journal of Molecular Medicine, 77, 386-392. http://dx.doi.org/10.1007/s001090050365 
Scientific Research Publishing (SCIRP) is one of the largest Open Access journal publishers. It is currently publishing more than 200 open access, online, peer-reviewed journals covering a wide range of academic disciplines. SCIRP serves the worldwide academic communities and contributes to the progress and application of science with its publication.

Other selected journals from SCIRP are listed as below. Submit your manuscript to us via either submit@scirp.org or Online Submission Portal.
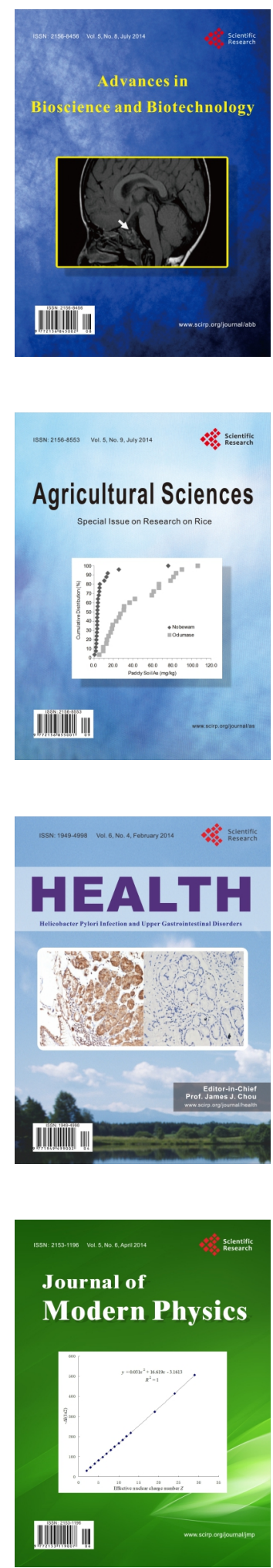
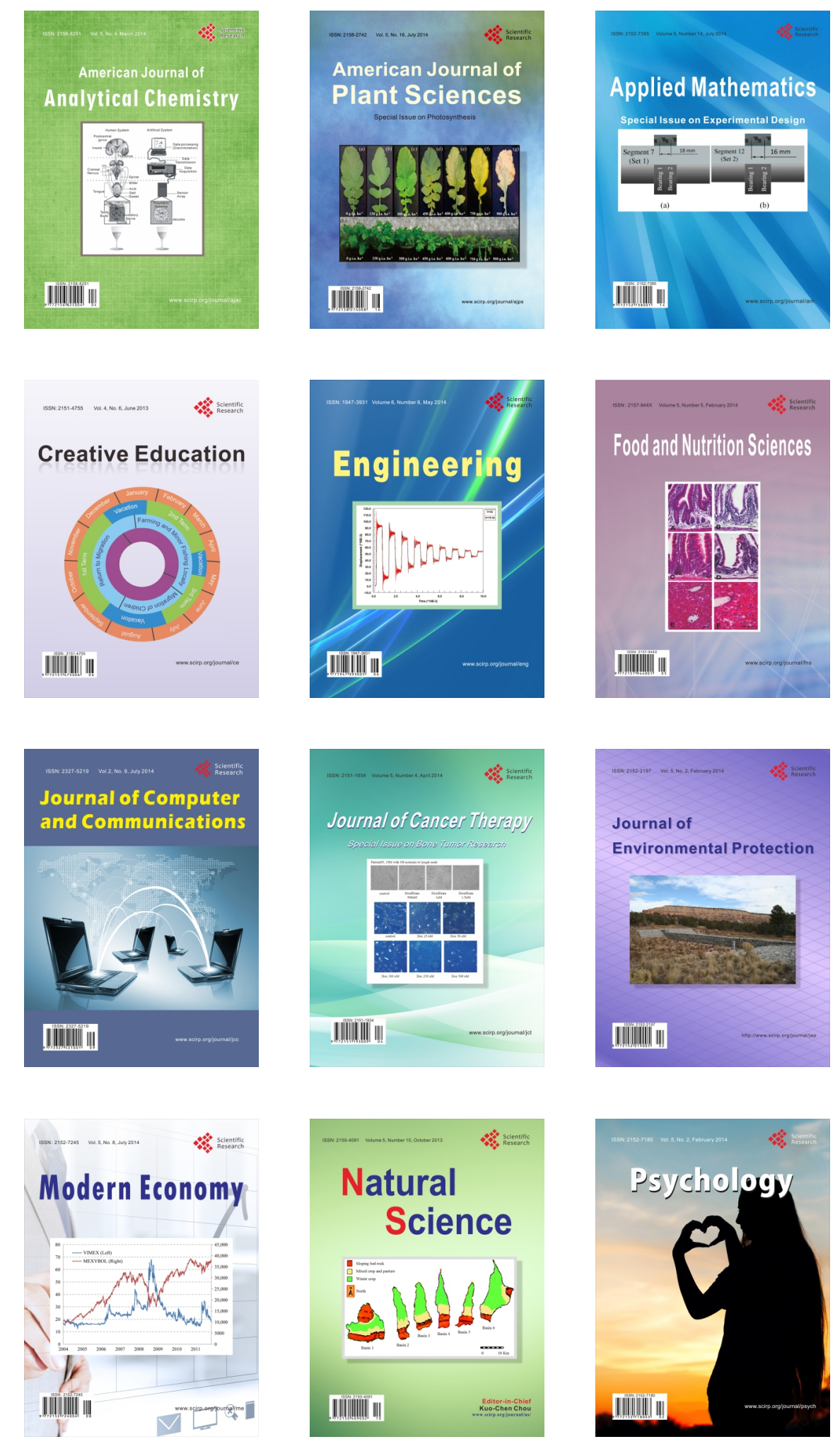